\title{
METABOLIC DERANGEMENTS AS INDICATORS OF PARTIAL HELLP SYNDROME
}

\author{
Suparna Roy1, Anindya Dasgupta ${ }^{2}$
}

${ }^{1}$ Assistant Professor, Department of Biochemistry, Calcutta National Medical College \& Hospital, Kolkata.

2 Professor \& HOD, Department of Biochemistry, Calcutta National Medical College \& Hospital, Kolkata.

\begin{tabular}{l}
\hline ABSTRACT \\
\hline BACKGROUND \\
Partial HELLP syndrome (PHS) can progress to fully developed HELLP syndrome, eclampsia and its grave consequences if not \\
diagnosed early with subsequent proper monitoring. Studies regarding changes in biochemical parameters in PHS in Eastern India \\
are scarce.
\end{tabular}

\section{MATERIALS AND METHODS}

This study was a descriptive comparative study. Biochemical and haematological parameters were assayed in 33 PHS cases and 35 control subjects in a case-control hospital-based observational study with an aim to compare their changes with the normal pregnant population. Serum levels of AST, ALT, bilirubin and LDH were measured by standard photometric methods. Blood haemoglobin and platelet count were measured using cyanmethemoglobin assay and automated cell counter respectively. Data were analysed for difference between mean values of study parameters between the case and control group. For assessing the strength of relationship between altered liver function tests and the degree of hypertension, bivariate correlation assay was performed. For all statistical analyses, the $\mathrm{P}$ value was considered to be significant at a level of $\mathrm{P}<0.05$ for $95 \%$ confidence interval.

\section{RESULTS}

Serum AST, ALT, indirect and total bilirubin and LDH levels were significantly higher in the case group with $\mathrm{P}$ values $<0.001$. Platelet count was within the normal reference range but significantly lower in the case group when compared to the control subjects.

\section{CONCLUSION}

In our study group, patients with PHS showed significantly higher levels of liver enzymes and indirect bilirubin. In the context of significantly low platelet count, it indicated increased haemolysis in PHS. However, in spite of having higher liver enzymes and increased haemolysis, platelet count was within normal reference interval. In conclusion, we suggest that in our PHS subjects with effective monitoring and early intervention, patients can be saved from poor foetal and maternal outcome of fully developed HELLP syndrome.

\section{KEYWORDS}

Partial HELLP Syndrome, Liver Enzymes, Platelet Count, Hypertension in Pregnancy.

HOW TO CITE THIS ARTICLE: Roy S, Dasgupta A. Metabolic derangements as indicators of partial HELLP syndrome. J. Evolution Med. Dent. Sci. 2017;6(84):5853-5856, DOI: 10.14260/jemds/2017/1271

\section{BACKGROUND}

Preeclampsia is defined as a systolic blood pressure and diastolic blood pressure more than 140 and $90 \mathrm{mmHg}$ respectively. Being a systemic disorder, Preeclampsia is confounded by several metabolic derangements other than hypertension. One of those syndromes is a conglomeration of haemolysis, elevated liver enzymes and decreased platelet counts known as HELLP that become clinically evident at a later stage of pregnancy after 37 weeks.[1] The major complications of this syndrome are due to macroangiopathy and coagulopathy evolving most commonly from hypertension. Several vital organs bear the brunt of this

'Financial or Other Competing Interest': None.

Submission 04-09-2017, Peer Review 07-10-2017,

Acceptance 12-10-2017, Published 19-10-2017.

Corresponding Author:

Dr. Anindya Dasgupta,

Professor and HOD,

Department of Biochemistry,

Calcutta National Medical College,

Kolkata-14.

E-mail: anindya653@gmail.com

DOI: $10.14260 /$ jemds $/ 2017 / 1271$ syndrome resulting in cortical blindness, cerebral oedema, haemorrhagic stroke, liver rupture and subarachnoid haemorrhage.[2-5] Major consequences of these organ damages are furthermore complicated by preeclampsia to a great extent. Elevated liver enzymes and serum bilirubin signify compromised hepatic function whereas decreased platelet count and increased haemolysis indicate increased risk for bleeding disorders for these particular varieties of preeclampsia patients. If not recognised at early stage, the outcome of this syndrome is grim due to development of neurological complications like strokes or other neurological deficits.[5]

Regarding the diagnosis and extent of symptoms, HELLP syndrome has been significantly inconsistent till now. Since Sibai[6] proposed strict criteria for the diagnosis of the "true HELLP syndrome", it has been observed that many women with severe preeclampsia may have laboratory abnormalities such as isolated haemolysis or low platelet count or elevated liver enzymes, without the complete HELLP syndrome. Women with partial HELLP syndrome (PHS) should be studied and managed separately from women with HELLP syndrome or severe preeclampsia.[7] 
This is mainly due to different opinions for defining this syndrome and the obscure nature of its pathogenesis. At its full expression, this syndrome consists of all of its characteristic features which have albeit a rare prevalence of $0.1 \%$.[1] Rather, many women with low platelet count or isolated elevated hepatic enzymes without the complete HELLP syndrome are identified with prevalence as much as 21 to $24 \% .{ }^{[8]}$ These patients are depicted as partial HELLP syndrome having any one or two of the symptoms of fully developed HELLP syndrome. Rate of caesarean section, eclampsia and preterm delivery are reported to be significantly greater than isolated hypertension of pregnancy, ${ }^{[9]}$ more commonly found in preeclampsia and it constitutes the partial HELLP syndrome.

In some Indian studies so far, although, the prognosis of partial HELLP syndrome is not as severe as the fully developed HELLP syndrome, still poor foetal outcome and number of caesarean section has been found to be significantly greater in comparison to the normal deliveries.[10] Keeping these factors in mind, the present study was designed to assess the relative importance of different metabolic derangements and their relationship with hypertension in patients diagnosed as partial HELLP in our region.

\section{MATERIALS AND METHODS}

\section{Study Design}

The present study was undertaken as a descriptive comparative study carried out in a tertiary care hospital in the Department of Gynaecology and Obstetrics and the Dept. of Biochemistry of a tertiary level medical college and hospital. Total sample size was 68 . The sample size was taken using the method of convenience.

Cases were selected from the Gynaecology and Obstetrics indoor ward from those patients suffering from pregnancyinduced hypertension (PIH) using the method of convenience. Patients lacking full criteria for complete HELLP syndrome, but having some of the diagnostic criteria for HELLP were considered to be suffering from partial HELLP and was confirmed by presence of at least any of the two laboratory criteria for full HELLP syndrome. Final selection of cases was done according to the following inclusion and exclusion criteria.

\section{Inclusion Criteria for Cases}

1. All pregnant women above 20 weeks of gestational age with $\mathrm{BP}>140 / 90 \mathrm{mmHg}$.

2. Patients with Pre-eclampsia/Eclampsia.

3. Patients having at least any of the two laboratory investigations for HELLP e.g. elevated liver enzymes, elevated serum bilirubin, low platelet count and elevated LDH level.

\section{Exclusion Criteria for Cases}

1. Patients having full HELLP syndrome.

2. Known case of liver and renal diseases.

3. Known case of haematological diseases.

4. Known case of Platelet disorders.

Selection of control subjects: Age-matched nonhypertensive pregnant women without any metabolic, endocrinological or any other pregnancy-related disorder were selected as controls. Following the above inclusion and exclusion criteria, finally we selected 33 cases and 35 controls.

\section{Ethical Considerations}

The study was permitted by institutional ethical committee and strictly adhered to the guidelines of the revised Helsinki declaration for human studies.

\section{Estimation of Laboratory Parameters}

For all laboratory tests, $5 \mathrm{~mL}$ of venous blood was obtained from the study subjects under aseptic conditions. Biochemical parameters were measured as follows:

a. Parameters for measuring liver function: Serum bilirubin was estimated by Jendrassik-Grof method. Aspartate transaminase (AST), Alanine transaminase (ALT) and Lactate dehydrogenase (LDH) were measured by IFCC approved kinetic method. All these tests were performed using the full autoanalyser from Transasia XL 600 following appropriate quality control measures. Coefficient for variation (CV) was found to be below 8 percent signifying the precision levels for these tests at acceptable level.

b. Measurement of haematological parameters: Haemoglobin in blood was measured by the standardised cyanmethemoglobin method. Platelet counts were measured in an automated cell counter.

\section{Statistical Analysis}

The data obtained were analysed for difference between mean values between the case and control groups by student's $t$ test. The strength of association between the different analytes in the case group was assessed by bivariate correlation study. For all tests, the level of significance was considered to be $\mathrm{P}<0.05$ for a $95 \%$ confidence interval. All statistical interpretations were carried out using the SPSS 20 software for Windows version.

\section{RESULTS}

Data obtained were first tested for their distribution pattern using the statistical tests for normal distribution. Tests for Kolmogorov-Smirnov and Shapiro-Wilks showed the data to be distributed normally. Graphical representation by box whisker plot (Figure 1) also suggested their normal distribution.

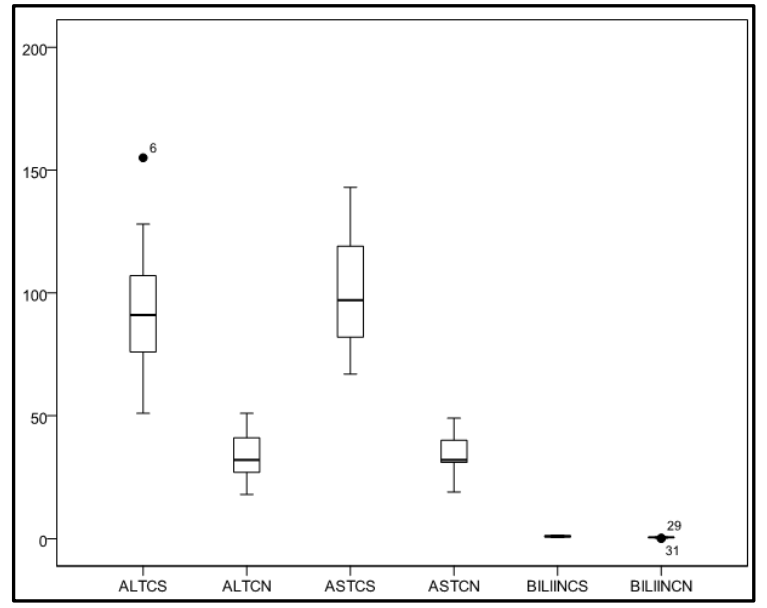

Figure 1. Box Plot showing the Distribution of Test Parameters for Liver Function in the Case Group 
CS: Case; CN: Controls; ALT: Alanine transaminase, AST: Aspartate transaminase; BILIIN: Indirect Bilirubin.

When compared with the control group, ALT, AST, indirect bilirubin and LDH levels were found to be significantly higher in the case group. On the other hand, haemoglobin percentage and platelet count in the case group, although within the reference range, showed significant lower values than the control subjects (Table 1).

\begin{tabular}{|c|c|c|c|c|}
\hline Parameters & $\begin{array}{c}\text { Cases } \\
\text { (Mean } \pm \text { SD) }\end{array}$ & $\begin{array}{c}\text { Controls } \\
\text { (Mean } \pm \text { SD) }\end{array}$ & t value & P value \\
\hline ALT (IU/L) & $91.75 \pm 24.3$ & $32.7 \pm 8.6$ & 13.31 & $<0.001$ \\
\hline AST (IU/L) & $98.6 \pm 21$ & $34.5 \pm 7.1$ & 16.77 & $<0.001$ \\
\hline $\begin{array}{c}\text { Indirect } \\
\text { bilirubin } \\
\text { (mg/dL) }\end{array}$ & $0.87 \pm 0.25$ & $0.44 \pm 0.13$ & 8.66 & $<0.001$ \\
\hline Platelets & $2.01 \pm 0.7$ & $2.45 \pm 0.49$ & -2.95 & 0.004 \\
\hline $\begin{array}{c}\text { SBP } \\
(\mathrm{mmHg})\end{array}$ & $152.8 \pm 22.9$ & $115.11 \pm 5.59$ & 9.27 & $<0.001$ \\
\hline
\end{tabular}

\begin{tabular}{|c|c|c|c|c|}
\hline $\begin{array}{c}\mathrm{DBP} \\
(\mathrm{mmHg})\end{array}$ & $104.78 \pm 13.3$ & $78.79 \pm 4.7$ & 10.70 & $<0.001$ \\
\hline $\mathrm{HB}(\mathrm{g} / \mathrm{dL})$ & $10.79 \pm 2.1$ & $12.54 \pm 0.79$ & -4.49 & $<0.001$ \\
\hline $\mathrm{LDH}$ & $\begin{array}{c}560.39 \pm \\
175.12\end{array}$ & $\begin{array}{c}167.97 \pm \\
28.26\end{array}$ & 12.89 & $<0.001$ \\
\hline $\begin{array}{c}\text { Bilirubin } \\
\text { (Total) }\end{array}$ & $\mathbf{1 . 3 1} \pm \mathbf{0 . 3 8}$ & $\mathbf{0 . 7 0} \pm \mathbf{0 . 0 3}$ & $\mathbf{8 . 0 8}$ & $<\mathbf{0 . 0 0 1}$ \\
\hline $\begin{array}{c}\text { Table 1. Difference between Mean Values of Study } \\
\text { Parameters as Evident from Independent t test }\end{array}$ \\
\hline
\end{tabular}

$P$ value is considered significant at a level of $p$ value $<0.05$ for $95 \%$ confidence interval.

The liver function parameters in the case group were found to be directly correlated to both the systolic and diastolic blood pressure (Table 2) suggesting their elevated levels to be directly proportional with the degree of hypertension of pregnancy.

\begin{tabular}{|c|c|c|c|c|c|c|c|}
\hline & & ALT & AST & BIL (IN) & Platelet & SBP & DBP \\
\hline \multirow{2}{*}{ ALT } & Pearson Correlation & 1 & $0.657^{* *}$ & $0.454^{* *}$ & -0.039 & $0.482^{* *}$ & $0.426^{*}$ \\
\hline & Sig. (2-tailed) & & 0.000 & 0.008 & 0.829 & 0.004 & 0.013 \\
\hline \multirow{2}{*}{ AST } & Pearson Correlation & $0.657^{* *}$ & 1 & 0.183 & -0.102 & $0.530^{* *}$ & $0.390^{*}$ \\
\hline & Sig. (2-tailed) & 0.000 & & 0.309 & 0.571 & 0.002 & 0.025 \\
\hline \multirow{2}{*}{ Indirect Bilirubin (mg/dL) } & Pearson Correlation & $0.454^{* *}$ & 0.183 & 1 & -0.189 & $0.443^{* *}$ & $0.456^{* *}$ \\
\hline & Sig. (2-tailed) & 0.008 & 0.309 & & 0.292 & 0.010 & 0.008 \\
\hline \multirow{2}{*}{ Platelet } & Pearson Correlation & -0.039 & -0.102 & -0.189 & 1 & -0.216 & $-0.362^{*}$ \\
\hline & Sig. (2-tailed) & 0.829 & 0.571 & 0.292 & & 0.227 & 0.038 \\
\hline \multirow{2}{*}{ SBP } & Pearson Correlation & $0.482^{* *}$ & $0.530^{* *}$ & $0.443^{* *}$ & -0.216 & 1 & $0.823^{* *}$ \\
\hline & Sig. (2-tailed) & 0.004 & 0.002 & 0.010 & 0.227 & & $<0.001$ \\
\hline \multirow{2}{*}{ DBP } & Pearson Correlation & $0.426^{*}$ & $0.390^{*}$ & $0.456^{* *}$ & $-0.362^{*}$ & $0.823^{* *}$ & 1 \\
\hline & Sig. (2-tailed) & 0.013 & 0.025 & 0.008 & 0.038 & 0.000 & \\
\hline
\end{tabular}

${ }^{*} \mathrm{P}$ value significant at $\mathrm{P}<0.01$ level, ${ }^{* *} \mathrm{P}$ value significant at $\mathrm{P}<0.001$ level.

\section{DISCUSSION}

Although HELLP syndrome or partial HELLP syndrome are variants of PIH, still they deserve more serious and earlier attention than normal PIH patients due to involvement of multiple organs that include some of the most vital organs like liver and kidney. As the whole body perfusion status and immunological status are changed in pregnant women in comparison to their non-pregnant counterparts, hypertension in pregnancy is always accompanied with graver consequences. Neutrophil activation, their degranulation and their elastase activities are reported to be significantly higher in pregnancy with hypertension.[11] Oxidative stress-induced tissue damage has been also found to occur more prominently in PIH.[12] Furthermore, the autoregulatory system of different vital organs like brain becomes inefficient at a blood pressure in excess of $150 \mathrm{mmHg}$ resulting in extravasation of plasma into tissue and consequent oedema.[13] All these factors induce cellular oedema, ischaemia and immunological assault that are manifested in liver tissues as hepatocellular necrosis and elevation of liver enzymes.[14] In our study, we have shown this with elevated hepatic enzymes beyond their reference intervals in the case group (Table 1). Moreover, the raised hepatic enzymes showed direct linear relationship with the degree of both systolic and diastolic hypertension in the case group (Table 2) that indicated hypertension-induced organ damages in these patients' progress in unabated manner with elevated blood pressure leading to unlimited tissue damage.

HELLP syndrome is one of the most severe varieties of PIH. PHS, in spite of showing an incomplete spectrum has been found to progress to fully developed HELLP syndrome with its complications. Moreover, PHS itself has been reported to induce several complications including significantly more haemolysis and lower platelet count both of which are accompanied with significantly worse foetal and maternal outcome both. Many authors have used elevated total LDH (usually $>600 \mathrm{U} / \mathrm{L}$ ) as a diagnostic criterion for haemolysis. There are five different isoforms of LDH, and only two of them, LDH1 and LDH2, are released from ruptured red blood cells. In most women with severe preeclampsiaeclampsia, the elevation in total LDH is probably caused mostly by liver ischaemia. In our study also, we have found a significantly higher value of LDH that is very close to the suggested cut-off value for impending haemolysis (Table 1). Keeping in track with these observations, the platelet count in our case group, in spite of being within the reference interval, 
has been found to be significantly lowered than that in the control group (Table 1). Thus, the PHS heralds a potentiality for development of full blown HELLP syndrome with severely low platelet count and much higher levels of LDH values.

Haemolysis, defined as the presence of microangiopathic haemolytic anaemia, is the hallmark of HELLP syndrome. The role of disseminated intravascular coagulation (DIC) in preeclampsia is controversial. Most authors do not regard HELLP syndrome to be a variant of DIC because coagulation parameters such as prothrombin time, partial thromboplastin time, and serum fibrinogen are normal. However, some studies have reported DIC in HELLP syndrome[15] that could make the situation worse. In our case group, we found a significantly lower level of haemoglobin (Table 1) in our case group with raised values of indirect bilirubin indicating increased haemolysis in partial HELLP also.

\section{CONCLUSION}

The findings of our study showed that PHS is accompanied with significant amount of hepatocellular damage and haemolysis that are directly related to the degree of both systolic and diastolic blood pressure. Although, they are in lesser extent than the full HELLP, still they merit special attention for avoiding their progression into fully developed HELLP syndrome and preventing the lethal complications of eclampsia. We propose that patients suffering from PHS need proper monitoring using both clinical and biochemical parameters for preventing their progression to fully developed HELLP syndrome.

\section{REFERENCES}

[1] Okada T, Kanagaki M, Yamamoto A, et al. Magnetic resonance imaging of vascular encephalopathy related to pregnancy. Neurol Med Chir (Tokyo) 2013;53(8):520-5.

[2] Yoshikane T, Miyazaki T, Aoki S, et al. A case of HELLP syndrome resulting in eclampsia with non-aneurysmal subarachnoid hemorrhage. No Shinkei Geka 2013;41(2):135-41.

[3] Zatelli M, Comai A. Spontaneous rupture of the liver in a patient admitted for subarachnoid hemorrhage. Int J Surg Case Rep 2015;6:15-8.
[4] Block HS. Neurological complications of pregnancy. Curr Neurol Neurosci Rep 2016;16(7):67.

[5] Miller EC, Yaghi S, Boehme AK, et al. Mechanisms and outcomes of stroke during pregnancy and the postpartum period: a cross-sectional study. Neurol Clin Pract 2016;6(1):29-39.

[6] Sibai BM. The HELLP syndrome (hemolysis, elevated liver enzymes, and low platelets): much ado about nothing? Am J Obstet Gynecol 1990;162(2):311-6.

[7] Audibert F, Friedman SA, Frangieh AY, et al. Clinical utility of strict diagnostic criteria for the HELLP (hemolysis, elevated liver enzymes and low platelets) syndrome. Am J Obstet Gynecol 1996;175(2):460-4.

[8] Van Dam PA, Renier M, Baekelandt $M$, et al. Disseminated intravascular coagulation and the syndrome of hemolysis, elevated liver enzymes, and low platelets in severe preeclampsia. Obstet Gynecol 1989;73(1):97-102.

[9] Abbade JF, Peracoli JC, Costa RA, et al. Partial HELLP syndrome: maternal and perinatal outcome. Sao Paulo Med J 2002;120(6):180-4.

[10] Mallesera A, Kanta SR, Shivappa P, et al. A clinical study of HELLP syndrome in a tertiary health care system. Int J Reprod Contracept Obstet Gynecol 2016;5(12):4196-9. www.ijrcog.org.

[11] Greer IA, Haddad NG, Dawes J, et al. Neutrophil activation in pregnancy-induced hypertension. $\mathrm{Br} \mathrm{J}$ Obstet Gynaecol 1989;96(8):978-82.

[12] Wisdom SJ, Wilson R, McKillop JH, et al. Antioxidant systems in normal pregnancy and in pregnancyinduced hypertension. Am J Obstet Gynecol 1991;165(6 Pt 1):1701-4.

[13] Cipolla MJ, Kraig RP. Seizures in women with preeclampsia: mechanisms and management. Fetal Matern Med Rev 2011;22(2):91-108.

[14] Mammaro A, Carrara S, Cavaliere A, et al. Hypertensive disorders of pregnancy. J Prenat Med 2009;3(1):1-5.

[15] Garg R, Nath MP, Bhalla AP, et al. Disseminated intravascular coagulation complicating HELLP syndrome: perioperative management. BMJ Case Rep 2009;2009:bcr 10.2008.1027. 